\title{
A critical examination of developments in nursing doctoral education in the United States
}

\author{
Shaké Ketefian ${ }^{1}$ \\ Richard W. Redman ${ }^{1}$
}

\begin{abstract}
Graduate nursing education in the United States is undergoing major transformations, as a result of factors both within nursing and in the larger society. Objective: In this paper the authors examine the trends and factors that are influencing the changes, especially in doctoral education, for both nurse scientist and advanced practice preparation. Conclusion: The paper provides a background that serves as context, it gives an overview of the PhD and the DNP degrees, focusing on the recent changes and identifying the most compelling issues and concerns, ending with a series of recommendations.
\end{abstract}

Descriptors: Education, Nursing, Graduate; Nursing.

${ }^{1}$ PhD, Professor, School of Nursing, University of Michigan, Ann Arbor, MI, United States.

Corresponding Author:

Shaké Ketefian

University of Michigan. School of Nursing

Bridle Pass, 3917

48018, Ann Arbor, MI, United States

E-mail: ketefian@umich.edu
Copyright (c) 2015 Revista Latino-Americana de Enfermagem This is an Open Access article distributed under the terms of the Creative Commons Attribution Non-Commercial License (CC BY-NC).

This license lets others distribute, remix, tweak, and build upon your work non-commercially, and although their new works must also acknowledge you and be non-commercial, they don't have to license their derivative works on the same terms. 


\section{Introduction}

Graduate education in nursing in the United States is undergoing a major transformation at present. A number of factors are converging to create these changes and the final results, although not entirely clear at present, are likely to change the landscape of graduate education in nursing in fundamental ways. The rapid development of the clinical practice doctorate since 2004, the doctor of nursing practice or DNP degree, is shaping the preparation of nurses for advanced practice roles and is impacting the role of the master's degree ${ }^{(1)}$. At the same time, a growing need for more nurse scientists is resulting in major changes in PhD education which include an emphasis on entry into research training at much earlier stages of a nursing career $^{(2)}$. The changes under way are intended to increase the cadre of nurse scientists and advanced practice nurses needed to address the pressing health problems in society and to expand the number of nurses needed in the future, given the rise in patient population expected as a result of the Affordable Care Act (ACA). While these types of changes are occurring primarily in the U.S., the models for graduate nursing education have often influenced approaches to graduate education in other countries. These changes could have global implications in the near or distant future.

This paper examines the major educational and social trends and the resulting changes that are occurring in graduate preparation for nurse scientists and advanced practice nurses in the U.S. The developments in both PhD and DNP education in nursing will be examined as they have been evolving over the last 10 years. We first provide a background by way of context; we then present an overview of each degree, identify and examine the critical issues, compare/contrast the two programs and the contributions of graduates of each type of program. Based on curricular features we will identify how faculty who teach in graduate nursing programs are being affected. Finally, based on findings and current realities, we offer recommendations for consideration.

\section{Background and Overview of the PhD in the United States}

Doctoral degrees in nursing have been offered since $1933-34$ by Teachers College, Columbia University and New York University. At that time the initial offering was the Doctor of Education Degree (EdD) by both institutions. By the mid-1960s there were six universities offering nursing doctorates, with degrees titled as EdD, PhD, DNS, or DNSc. Expansion of program offerings continued, gaining momentum in the mid1980 s with the move of the nursing research enterprise under the National Institutes of Health (NIH), first under a new Center for Nursing Research, and a few years later, under a full-fledged Institute for Nursing Research (NINR).

NINR has been funding nursing research through training programs as well as research support to individual scientists investigating nursing phenomena, using existing funding mechanisms within NIH. The training programs are for PhD study and for postdoctoral research, funding made either through institutional grants or to individual applicants directly. In addition, NINR has an intramurally funded program as well. There have been other funders for research or research training, but none has been as influential as the Federal government via the $\mathrm{NIH}$.

Doctoral programs continued to expand through the decades, increasing options available to nurses; concurrently, nursing adopted $\mathrm{NIH}$ values and instituted career trajectories that prevailed at NIH and its institutes. For a while doctoral degree types proliferated, but that trend was discontinued, as most schools offering nursing doctoral level study were focused on research - both its training and for the study of nursing science. Thus, the majority of schools have converted their degrees to the $\mathrm{PhD}$, both prospectively and retrospectively, and are authorizing their past graduates to use the PhD designation. The new designation in use for programs focused on research preparation is "research-focused doctoral programs." In 2014 there were 132 such programs, a growth from 101 a decade earlier(3).

General satisfaction is expressed about the state of the $\mathrm{PhD}$, yet there are some areas that require attention. The first issue is the unevenness in the research mentoring process and the extent to which doctoral students systematically work with faculty on funded projects. This unevenness exists both across schools as well as within a given school. The reasons vary, the most obvious one is that not all faculty members who 
mentor students have funded projects, and secondly, many PhD students hold full-time jobs and do not spend time on campus beyond the hours required for courses. The second issue of concern in PhD programs has to do with the need to prepare graduates for faculty roles and teaching competence, given that over $80 \%$ of graduates tend to go into teaching, and how to make space for this within the curriculum. This issue, unlike the first, has been addressed somewhat; since this issue has been a cross-disciplinary concern, graduate schools on many research university campuses have been involved and it was also addressed through a national/international project titled Re-Envisioning the PhD, and nursing has benefited greatly from the initiative; it is well-described by two key facilitators of the project, based on the campus of the University of Washington's Graduate School $^{(4)}$.

\section{Background and Overview of the DNP Degree in the U.S.}

In 2004, the American Association of Colleges of Nursing ${ }^{(5)}$ published a position statement on a doctorate in nursing practice, a degree that would align nursing with other health professions, and would prepare individuals for the highest level of practice. It further projected that by the year 2015 the DNP should replace the master's level preparation for advanced practice. At that time, four practice-focused programs existed, each offering its own conception of what such a degree might look like. In the decade since the position statement we have seen phenomenal growth in the DNP, which now stands at 243 , with several others in the preparation stage(3). Now that we are in 2015, very few schools have closed their master's programs in advanced practice. While the number of programs have grown, variations are evolving in the DNP program structure and content - with some offering the degree to post-baccalaureate students including BSN graduates following four years of study in nursing, as well as BS graduate of other disciplines enrolled in nursing as a second career in an accelerated format (14-16 months in length); some other DNP programs require applicants to have a master's degree in nursing. It would appear that the BSN entrants would receive advanced practice component during their DNP study, while MSN graduate entrants who have attained the advanced practice (APRN) credential would focus on content related to health policy, quality improvement (QI), leadership, management and other relevant topics, with no additional clinical content, as they would have obtained clinical expertise during master's study. According to Minnick and colleagues' study(6), who collected their data in $2011,48 \%$ of reporting schools offered the DNP only to MSN holders, whereas the other $52 \%$ offered the DNP to both BSN or MSN holders.

\section{Issues for Consideration}

We now identify and discuss several issues that are surfacing in the literature and are apparent in nurse educators' discourse at national conferences.

\section{Program length}

During the developments described above, there was increasing recognition of the fact that $\mathrm{PhD}$ study was taking too long, that there were major gaps in nurses' academic careers, first between the bachelor and master's degrees, and then between the master's and PhD study, whereby the typical age at the start of the PhD was mid- to late 30's and average age at graduation in the mid 40's; most importantly, that this picture had not changed over decades, and that concerted steps needed to be taken to change the situation. The concerns were connected not only to individuals in terms of the limited number of years during which they could be productive scholars, but there was concern from both the perspective of the profession and the nation as a whole, in that this late start of scholarly productivity deprived the nation and the profession of the potential contribution these individuals could make if their scholarly careers were to begin earlier in their lives.

Some isolated initiatives had begun in the late 1990's and early 2000's*, but the issue did not gain wide visibility and momentum until the report of the Institute

\footnotetext{
* In the late 1990s Josiah Macy, Jr. Foundation supported a 5-year project at the University of Michigan School of Nursing to enable early progression of bachelor degree graduates to enter PhD study soon after their graduation. Five students were supported each year. The project was subsidized through University funding in its later years. Around the same time the NINR indicated that institutions could use funds from their institutional National Research Service Awards to support early entry students (previously funds could not be used until students had completed the master's degree requirements. Another initiative similar to Michigan's was that at the University of Wisconsin, Madison, which has an early-entry option to move accomplished undergraduates to PhD study.
} 
of Medicine ${ }^{(7)}$ addressed this and related issues. In that report jointly supported by the IOM and Robert Wood Johnson Foundation ${ }^{(8)}$, they recommended increased educational level for nurses, recommending that 80 percent of staff nurses be bachelor degree holders (at present the ratio of BSN to ADN degree holders is about 50/50). They further recommended doubling the number of $\mathrm{PhD}$ degree holders in nursing. Thus the emphases were on addressing the nursing shortage, improving quality and increasing the overall impact of nurses within the health care system. Since the completion and release of the report RWJ has assumed the lead role in implementing the recommendations of the IOM report. As well, others have joined in providing their support at the implementation phase; two examples are the Hillman Foundation ${ }^{(9)}$, and the Jonas Foundation. Collectively, these foundations have set the pace and created an environment within which nursing and nursing education are now operating. Together, these foundations are using the power of their funds to impose change. An example of this power and influence is the stipulation that the $\mathrm{PhD}$ be completed within three years, when in reality the circumstances are so variable that some flexibility may be required.

\section{Curricular issues}

Each type of professional program is expected to adhere to programmatic offerings that will prepare entrants to function in the manner specified in the conception of the program in order to meet a given societal need. The PhD was conceived as the scientific degree, whereby recipients of the degree will conduct rigorous research, develop and test scientific theories and generally contribute to the knowledge base of the discipline. It is now the case that some concerns have been expressed, such as the need to provide knowledge and experiences in teaching/learning processes to PhD students, and more hands-on research experience for students. Yet, generally, there has been satisfaction with the program content and the quality of individuals who function in ways expected of holders of this degree. Approximately $80 \%$ of graduates go into college/university teaching, where they combine teaching with research, and $20 \%$ go into other types of activities, such as private practice, health policy, management, consulting work and the like.
The IOM report ${ }^{(7)}$ and recommendations have led to changes or created the climate within which change can occur. Some of the Foundations that are supporting PhD study are specifying three years of funding per student which in turn has led some schools to change their entire curricular offerings, and requiring that students complete their study within three years on a full-time basis. It makes a big difference if the student is post-baccalaureate or post master's at entry, as to whether three years are sufficient for program completion. Some sample programs indicate heavy component of designs, methods, and statistics, a substantive focus and a dissertation. A $4^{\text {th }}$ year is allowed, if needed, to complete the dissertation. It is not clear how the substantive focus is offered: whether the format is independent study or in seminar form. This is a major change from what had evolved in nursing from the late 1980's to the present, whereby institutions did not only focus on research and research methods but on areas of science in nursing, and research was taught within the context of nursing, analyzing and critiquing scientific works in the discipline, and identifying gaps in knowledge for further study. In this sense the current changes in PhD programs, though not yet a firm trend, have opened the way and more are likely to follow. These changes are unfortunate indeed, as they potentially could take nursing PhD education back by 30 years.

With respect to the DNP, it has been conceived as an advanced practice degree, but the graduates are mainly taking faculty positions for which the program generally does not prepare them; a smaller number are taking management and leadership roles. Further, given the mix of students who enter DNP study (post-baccalaureate and post master's) their program of study has to be different of necessity. Post-baccalaureate students have to acquire clinical expertise, and clinical leadership skills, traditionally taught at the master's level, whereas post-master's students do not need that content, and can focus on the other content designed to augment clinical expertise, such as evidence-based practice (EBP), quality improvement techniques, translation of research evidence to clinical practice and policy for the betterment of patient care, and addressing systemwide concerns to improve systems to be receptive to change and ongoing improvements ${ }^{(10)}$. Those MSN/DNP graduates appear to be functioning well in faculty roles, 
teaching clinical subjects at various levels of study. There is less information available on BSN/DNP graduates, as they are more likely to need mentoring and guidance in whatever roles they undertake. Another important variable has to do with the capstone project, and the extent to which there is variation across the two groups of students; however, there is not sufficient information available at this time to comment on this matter.

\section{Faculty roles}

Questions have been raised as to the employability and/or effectiveness of both DNP and PhD graduates who were post-baccalaureate entrants to their programs. Substantive concerns raised at the time of hiring have to do with what these individuals will be able to do or teach, and how they might be mentored gradually to become effective and productive professionals. An important practical question is whether DNP graduates should be hired on the tenure track and whether they should be given tenure on whatever track. Decisions regarding these can be answered only in reference to the type of institution. For a major research institution where research and scholarly productivity are conditions for promotion and tenure, the fit would not be good for a DNP graduate; whereas in institutions where the mission heavily emphasizes teaching, these graduates may be hired and may even be tenured if they prove to be competent and productive teachers, demonstrating continuing growth. The reverse would be the case for a PhD graduate where type of institution that would be a good fit is a research-intensive one that both values research activity and provides resources and facilitation to enable research. Yet, there is an idea at large that research-universities do not value teaching. This is far from the truth; most such institutions take various steps to assist the new PhD graduate joining the faculty ranks to acquire teaching skills and develop a good grasp of the faculty role. The career trajectory of a $\mathrm{PhD}$ graduate in research-intensive settings has been charted clearly, as influenced by the NIH. However, at this time it is not clear what the trajectory is for the DNP graduate, perhaps because choice of career is not aligned with the education received, and partly due to its being barely a decade old degree. Nevertheless, this is something the profession has to address in the near future. As well, the profession has to determine whether the DNP is to be re-purposed to meet the needs arising from the well-documented faculty shortage ${ }^{(11)}$.

\section{PhD and DNP: How do They Compare?}

A number of institutions offer both the PhD and the DNP. The extent to which there is ongoing interaction between the students and faculty of these programs varies. Different views appear in the literature concerning this matter. Some authors maintain that interactions across the student groups can create synergies and can help "accelerate the translation of nursing research to

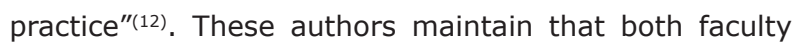
and student collaboration between the two programs "provide new approaches for translating research into practice and generating practice questions in need of further scientific study"(12).

On the other hand, many authors writing on the DNP/PhD topic are silent on the matter of interactions between the two groups, especially among students. As the two groups have distinctive goals, one can argue that to help inculcate the unique missions of the programs it may be best to keep faculty and students of the two programs separate. From a practical standpoint in settings where both programs are taught, interactions and collaborative projects are likely to be easier than in settings that have only one of the programs. However, beyond feasibility and ease, it is not known what benefits or advantages actually accrue as a result of ongoing interactions of either student groups or faculty groups. An argument can be advanced that ongoing interactions between PhD and DNP ht serve to dilute the uniqueness of either program.

Concern is apparent in the literature about instituting a DNP program in settings offering the PhD; PhD-prepared faculty are being called upon to teach in DNP programs in such settings; in addition, when DNP programs are instituted where no PhD program exists, faculty from PhD programs in other institutions are invited to teach in those DNP programs ${ }^{(6)}$. This matter should be of concern to the profession, as it takes qualified faculty away from what should be their primary responsibility, which is to conduct their own research and mentor their PhD students.

Sebastian and Delaney ${ }^{(12)}$ further point out that DNP programs' emphasis on "population health, informatics, and 
policy," present challenges "because not all current faculty members may have expertise in those areas" (p. 454). This type of concern expressed from deans, along with the apparent use, in DNP programs, of PhD-prepared faculty who already have major responsibilities in $\mathrm{PhD}$ programs, may suggest that capacity for DNP may be limited, and that nursing may be shifting resources from existing programs (BSN, MSN, PhD) to run 243 additional programs. Despite the argument by Edwardson ${ }^{(13)}$ that the two degrees should be complementary, Melnyk ${ }^{(10)}$ (p. 444) argues that a common goal exists across the two programs along with unique curricular content for each of the programs. The common goal is improved patient/population/policy outcomes. The DNP goals relate to EBP and translation of "external" evidence, generation of "internal" evidence, mentorship of others in EBP, and creation of systems to sustain it. The PhD goals are generation of research / external evidence to inform practice, extension of science, and developing evidence-based theories (Regarding external and internal evidence**).

$\mathrm{Grey}^{(14)}$, in reflecting on the national picture, as an invited guest of an invitational conference on the DNP by a regional group of deans, reflects on the fast proliferation of these programs, their great variation in curriculum, program length, objectives and outcomes (p. 462). Grey further points out that in 2004 when the AACN deans voted to approve the DNP as the advanced practice degree, they did so without evidence that the current advanced practice preparation in place was inadequate ${ }^{(14)}$. Such variations across program elements identified by this and other authors raise concerns about how and whether these programs are able to meet the accreditation criteria, and how nursing can assure the public about the competence level of DNP graduates possessing a common set of competencies.

A word about the culminating experiences in the two programs. The dissertation required of $\mathrm{PhD}$ students is intended to demonstrate the student's grasp of a significant issue in her/his field, along with attendant methodologies, demonstrate originality and scholarly approach in the conduct of the project, and make a contribution to the field. In the last several decades research intensive institutions have guided students to select topics that are within the stated national priorities of the NIH and/or the discipline, and have encouraged students to view the dissertation as the beginning step in their future program of research. These steps make it more likely that the results of such a program of research will have significance and will contribute to knowledge.

In the case of the DNP, the capstone project is the equivalent to the dissertation. It may be an independent research project (in the case of about $50 \%$ of programs), or evidence-based, change, leadership, synthesis, or translational research $\operatorname{project}^{(14)}$ (p. 463); this author reports that a random survey of schools offering the DNP revealed that most schools offer one research course and one statistics course, similar to what is required in a master's program ${ }^{(14)}$ (p. 463). It is hard to imagine a student a conducting a high quality independent research project or a translational research project after one research and one statistics course. Here too, it must be noted that there is a mismatch between the curriculum offerings and the level of scholarly performance expected of the students.

\section{Implications for International Nursing}

Nursing in the U.S. has historically been viewed as being influential by our international colleagues, thus they look toward developments in our country very carefully. Those of us who travel overseas are asked about developments and our views, in this case, about the DNP, and most importantly, they wish to know our advice on whether they should be offering the DNP.

In most instances, advanced practice nursing is absent from most settings, with the exception of nurse midwifery, but generally there is no foundation on which to build an advanced practice role. As well, in some countries there may be more physicians than nurses; when this phenomenon exists, nursing schools have difficulty securing clinical placements for nursing students. Yet, some of our international colleagues have received advice from U.S. colleagues that they indeed should move to offer DNP programs. Greater caution is indicated by us so that our colleagues overseas are not misled and can assess our own situation and realities for themselves, given relevant data.

\footnotetext{
** External evidence is "evidence generated through rigorous research"....internal evidence is "evidence generated through outcomes management, QI, and EBP projects"(10) (p. 443).
} 


\section{Conclusions and Recommendations}

Several recommendations suggest themselves as a result of the above overviews and analyses; we list them below without the intention of being exhaustive. Whether the two degrees are seen competitive or not, the fact remains that the resources have not increased appreciably to accommodate the rapid increase in DNP programs; thus, we must assume that the two programs compete for the limited resources available, which most likely will have repercussions in faculty overload and in other ways as well. While the recommendations below were not developed specifically to address resource issues, when implemented, they might allay to some extent the resource constraints as well.

1. Great uncertainty and lack of standardization surrounds the DNP. The AACN and the accrediting body should clearly articulate and hold all providers of the degree to the same standards. These include the need for clear mission, goals, outcome competencies and curricular content and practicum experiences to achieve the goals. Study of the variation and quality in DNP programs is underway by groups within the AACN at present and those reports are expected to appear later in 2015.

2. The fact that nursing has not developed content in nursing for advanced practice beyond the master's level makes the decision by DNP programs to offer advanced practice content to post-baccalaureate students in these programs somewhat strange and misleading; nursing has well established programs for advanced practice, their oversight, certification, etc., are clear and well recognized. The logic of advocating the closure of master's programs and assigning the task for the award of advanced practice nursing credentials at the DNP level, thus creating major upheavals strains logic. Currently post-baccalaureate students are said to focus on advanced practice while in the DNP program, whereas the post-master's students focus on leadership, policy, QI, evidence-based practice, knowledge translation and similar topics. We therefore recommend that the DNP be offered only at the post-master's level (assuming that the MS degree holder has focused on advanced practice), and existing master's programs continue offering advanced practice nursing.

3. There is a mismatch between the DNP educational preparation and the employment the graduates are seeking. The stated goal of the DNP is advanced practice to improve patient care, but the majority are taking faculty positions for which their education has not prepared them, and in the case of some post-master's graduates, they are taking management positions; thus, the goals of the program are not achieved. There is a need to investigate why this phenomenon exists and what can be done to align the educational goals with the employment setting. Conversely, if the goal is to address the national faculty shortage, clarify this, and revise the program content to align with this new goal.

4. Great variation in research content has been noted across institutions offering the DNP, though the most typical appears to be one course in research and one in statistics. Yet, students are conducting translational and evidence-based studies; to be effective in producing high quality capstone projects, it is necessary to offer research methodologies and designs appropriate to those areas, along with relevant analytic techniques; it is also necessary to more clearly articulate the types of capstone projects that are feasible.

At the same time, PhD students are typically required to take intermediate to advanced research methods and analytic techniques. However, the extent to which they have opportunities to practice the relevant skills and work with faculty on funded projects is highly variable. There is therefore a need to standardize those experiences, and require these of all students.

1. There is a dearth of literature regarding the DNP practicum experiences on areas identified for postmaster's delivery, i.e., leadership, change, QI, and evidence-based practice; it is necessary to articulate these more clearly and demonstrate that the existing systems are capable of assisting nursing programs in providing such practicums. At the same time, it is suggested that new technologies now available 
through simulation be explored as strategies to augment didactic study of relevant subjects.

2. There is a need to offer content to both $\mathrm{PhD}$ and DNP graduates at the start of their first year of employment on faculty roles, in order to develop skills as teachers and faculties in higher education. This can be done through planned offerings or by setting up required content, and allowing individuals to meet the requirements in their own ways.

3. The role of the master's degree, for both DNP and $\mathrm{PhD}$ students, requires further examination. As mentioned previously, the master's in nursing as the foundation for advanced practice has stood the test of time. It also has grounded students in identifying questions arising from practice experiences that has guided knowledge development in nursing science. To simply abandon the role of the master's or ignore the value of some advanced experiences, without careful examination of this move in terms of curriculum in both types of programs, appears risky and unfounded.

4. The rapid move to three years of post-baccalaureate PhD education seems to be advancing without sufficient evidence that it is the right path for the best preparation for nurse scientists. While it may align nursing with the education pathways taken by some other basic scientists, the types of research conducted by nurses and the extended post-doctoral training seen in most basic sciences are at odds with the typical conduct of research in a laboratory. The current innovations in shorter PhD programs for nurses require careful evaluation, both formative and summative, before they are rapidly adopted by all program nationally.

We have identified several issues we consider important with respect to developments in doctoral education in the U.S. and have suggested approaches for addressing them. These are relevant for the U.S. context, but may not be for other settings. As is often the case during times of rapid change, decisions are sometimes made when insufficient evidence is available to support them. Given the long-term implications of many of the decisions made recently in graduate nursing education, careful evaluation and a deliberative progression forward is important to ensure that evidence is available to guide future directions.

\section{References}

1. Auerbach DI, Martsolf G, Pearson ML, Taylor EA, Zaydman M, Muchow A, et al. The DNP by 2015: A study of the institutional, political, and professional issues that facilitate or impede establishing a post-baccalaureate Doctor of Nursing Practice program [Internet]. Santa Monica, CA: Rand Health; 2014. [acesso 3 nov 2014]; Disponível em: http://whww.aacn.nche.edu/dnp/DNPStudy.pdf.

2. National Academy of Sciences. Advancing the nation's health needs: NIH research training programs. Washington, DC: National Academies Press; 2005.

3. American Association of Colleges of Nursing (AACN). Enrollment and Graduations in Baccalaureate and Graduate Programs in Nursing: 2013-2014. Washington, DC: AACN; 2014.

4. Woodford BJ, Nyquist JD. Re-envisioning the PhD project: Implications for the preparation for future faculty in nursing. In: Ketefian S, McKenna HP, editors. New York: Routledge; 2005. Doctoral Education in Nursing: International Perspectives, p. 71-85.

5. American Association of Colleges of Nursing (AACN). AACN position statement On the practice doctorate in nursing. Washington, DC: AACN; 2004.

6. Minnick AF, Norman LD, Donaghey B. Defining and describing capacity issues in U.S. Doctor of Nursing Practice programs. Nurs Outlook. 2013;61(2):93-101.

7. Institute of Medicine. The future of nursing: Leading change, advancing health. Washington, DC: National Academies Press; 2010.

8. Robert Wood Johnson Foundation New Careers in Nursing. Doctoral advancement in nursing: A roadmap for facilitating entry into doctoral education. Doctoral Advancement in Nursing (DAN) Project White Paper. [Internet]. 2013. [acesso 3 nov 2014]. Disponível em: http://www.newcareersinnursing.org/resources/danwhite-paper

9. Rita \& Alex Hillman Foundation. Hillman Scholars in Nursing Innovation [Internet]. 2014. [acesso 3 nov 2014]. Disponível em: http://www.rahf.org/grantprograms/scholars

10. Melnyk B. Distinguishing the preparation and roles of doctor of philosophy and doctor of nursing practice graduates: National implications for academic curricula and health care systems. J Nurs Educ. 2013;52(8):442-8. 
11. American Association of Colleges of Nursing (AACN) [Internet]. Nursing Faculty Shortage. 2014. [acesso 10 nov 2014]. Disponível em: http://www.aacn.nche.edu/ media-relations/fact-sheets/nursing-faculty-shortage.

12. Sebastian JG, Delaney CW. Doctor of nursing practice programs: Opportunities For faculty development. J Nurs Educ. 2013;52(8):453-61.

13. Edwardson S. Doctor of philosophy and doctor of nursing practice as complementary degrees. J Prof Nurs. 2010;26(3):137-40.

14. Grey $M$. The doctor of nursing practice: Defining the next steps. J Nurs Educ. 2013;52(8):462-5. 